\title{
A discrete event simulation for modelling Aljamarat Bridge rituals and evacuation scenarios
}

\author{
$\underline{\text { A.A. Owaidah }}^{\text {a }}$, D. Olaru ${ }^{\text {b }}$, M. Bennamoun ${ }^{\text {a }}$, F. Sohel ${ }^{\text {c, a }}$ and R.N. Khan ${ }^{d}$ \\ ${ }^{a}$ Department of Computer Science and Software Engineering, The University of Western Australia, Perth, \\ WA 6009, Australia, ${ }^{b}$ Business School, The University of Western Australia, Perth, WA 6009, Australia, \\ ${ }^{c}$ Discipline of Information Technology, Murdoch University, Murdoch, WA 6150, Australia, ${ }^{d}$ Department of \\ Mathematics and Statistics, The University of Western Australia, Perth, WA 6009, Australia.
}

Email: almoaid.owaidah@research.uwa.edu.au

\begin{abstract}
Hajj is the largest mass gathering event globally that occurs annually. It is a pilgrimage that lasts for about a week. The pilgrims perform rituals at different sites (The Grand Mosque, Mina, Arafat and Muzdalifah) in the city of Makkah, Saudi Arabia. Safety of the pilgrims is number 1 priority for the Saudi authorities and several new projects have recently been completed at the Hajj sites with a goal to improve proceedings. One of these projects was the redesign and construction of the Aljamarat Bridge at Mina City. This project was commissioned to mitigate severe crowd incidents at the bridge in previous years. The new bridge has greatly improved safety of pilgrims. However, unexpected hazards and accidents such as fire or gas leaks can occur, necessitating the evacuation of pilgrims from the bridge. This paper presents a model and simulation study of pilgrim evacuation from Aljamarat bridge using a Discrete Event Simulation (DES) tool called "ExtendSim". The tool was validated by modelling and simulation of three million pilgrims based on a strict scheduling system that distributes them on each level. Based on our methods of allocating specific evacuation routes at each level on the bridge, the evacuation modelling shows promising results when using six towers, resulting in a smooth process without any crowd buildup.
\end{abstract}

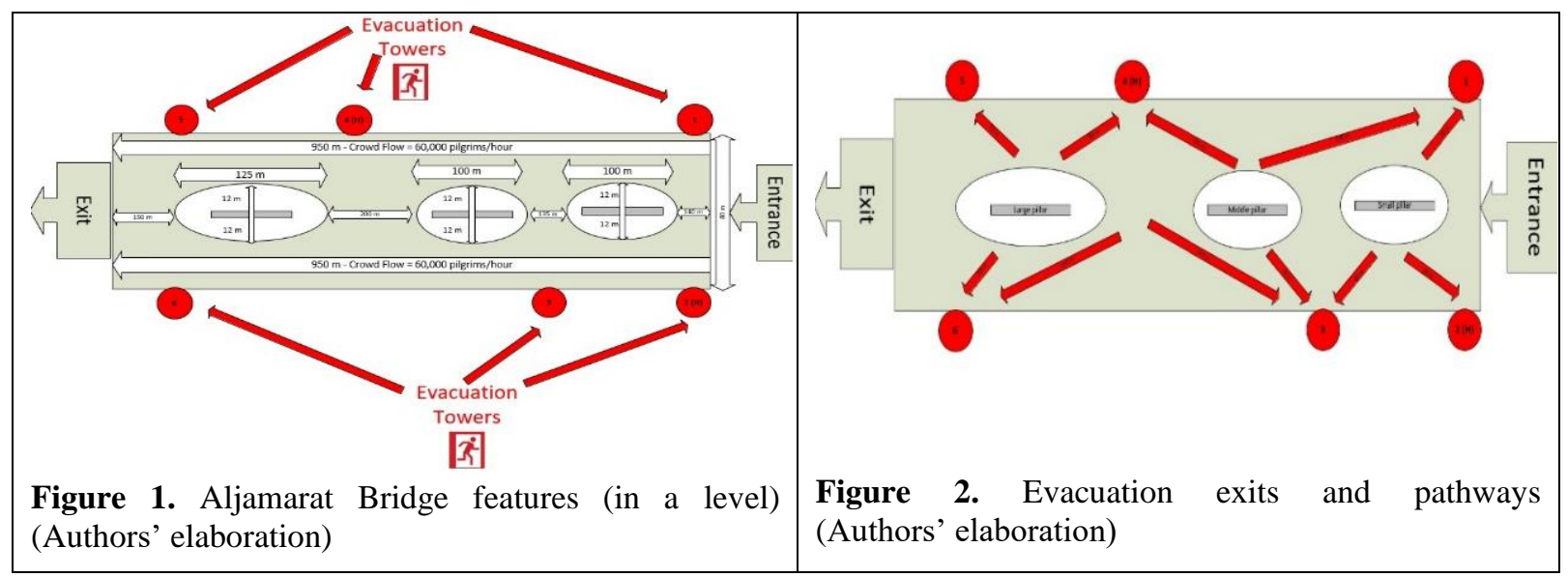

Keywords: Hajj, Aljamarat Bridge, crowd management, Discrete event simulation, evacuation modelling and simulation 


\section{INTRODUCTION}

Given the inevitable overcrowding, Mass Gathering (MG) events pose substantial challenges to organisers and relevant authorities in relation to crowd management, security, and emergency preparedness (Memish et al., 2012). These events attract crowds varying in size and complexity, and their planning and management need to account for spatial-temporal constraints (Aitsi-Selmi et al., 2016). Yet, crowd hazards and accidents have been recorded at many MGs (Aitsi-Selmi et al., 2016).

Hajj is one of the largest MG events worldwide and occurs annually usually with more than two million pilgrims (Reffat, 2012; Friberg and Hjelm, 2014; Haase et al., 2019). Hajj takes place annually, in Makkah, at a very specific time, during the $8^{\text {th }}-12^{\text {th }}$ of Dhulhijjah, the last month in the Islamic calendar (Yamin and Albugami, 2014). Hajj events consist of specific, fixed sequence of rituals at fixed locations and with strict spatial boundaries. In 2020 and 2021, due to the COVID-19 pandemic, the event was substantially reduced in size; yet, it is expected that numbers comparable to pre-2020 will return at Hajj in the post-pandemic era.

A number of features make Hajj a unique event: sheer size of the attendance; heterogeneity of the pilgrims; and specific order and time windows of the rituals. Managing the Hajj is a difficult, multifaceted task (Osman and Shaout, 2014). Pilgrims have different cultural backgrounds, speak different languages, and often display distinct and non-uniform behaviours during Hajj rituals (Alabdulkarim et al., 2016).

To manage pilgrim movements and ensure Hajj proceeds smoothly, the Ministry of Hajj, Kingdom of Saudi Arabia, has established six international establishments, an Arabic Gulf countries establishment, and an interior establishment (Khozium et al., 2012), with responsibilities for pilgrims from designated countries. The Ministry of Hajj together with the Ministry of Municipal and Rural Affairs of the Kingdom of Saudi Arabia (MOMRA) are in charge of designing the Hajj crowd management plan (Haase et al., 2019).

The focus of this paper is the Aljamarat ritual (Stoning the Devil at one or three pillars), performed during the $3^{\text {rd }}, 4^{\text {th }}$ and $5^{\text {th }}$ days of Hajj (Yamin and Albugami, 2014) in the holy site of Mina. The Aljamarat Bridge is a physically constrained venue (as discussed in 4.1) and the ritual occurs on all five levels of the bridge, following a unidirectional movement system to prevent counter flows and obstructions (Alaska et al., 2017).

In the past (1986-2006), interactions among pilgrims at Hajj have led to crowd incidents, and even resulted in deadly stampedes (Al-Kodmany, 2013). This triggered infrastructure changes, but also better prior planning by the authorities, using various possible scenarios to account for unexpected events (Reffat, 2012; Alabdulkarim et al., 2016). In the case of the Aljamarat Bridge, the crowd management plan includes timetabling of activities; designating specific routes; and developing schedules for each of the pilgrim groups (of size 250), depending on the location of their accommodation in Mina City (Al-Bosta, 2011; Muller, 2015; Haase et al., 2019). These processes are implemented to control the flows of pilgrims, allowing only a certain number of pilgrims to enter the bridge at a given time (Alaska et al., 2017).

Many approaches to model the Aljamarat ritual have been proposed in the literature. Given the focus on assessing the overall safety and efficiency of the ritual within the Hajj sequence, this paper models the rituals at the Bridge and develops evacuation scenarios from the bridge using Discrete Event Simulation (DES).

The structure of the rest of the paper is as follows. A review of related work of crowd modelling and simulation at Aljamarat Bridge and previous evacuation studies using DES or other simulation techniques is given in the next section. The paper then describes the Methodology and the implementation of the model using the ExtendSim software. Evacuation scenarios are explored and then results are presented in the Discussion. The paper concludes with a summary of the findings and recommendations for practice and future work.

\section{RELATED WORK}

Owaidah et al. (2019) reviewed important crowd modelling and simulation studies for Aljamarat Bridge for both normal and evacuation situations. The design of the Aljamarat Bridge is a 5-level structure (Still and Algahdi, 2003; Felemban et al., 2020). The modelling of the new bridge was done using Legion and Myriad 2 Agent-Based Modelling (ABM) packages, considering a maximum level of service of 4 pilgrims $/ \mathrm{m}^{2}$, a widely used international safety standard (Still and Algahdi, 2003). Legion was used for modelling and simulating crowd evacuation scenarios, and Myriad 2 for the evacuation, considering three different options: a random exit; the nearest exit; and all pilgrims choosing the same exit (Still, 2000; Al- Kodmany, 2013). This modelling focused on simulating normal and emergency evacuations as a worst-case emergency scenario. Each level is connected to towers, however the rates (p) of pilgrim evacuation for each level differ across the towers of the bridge: level $1=7,515 \mathrm{p} / \mathrm{min}$; level $2=5,295 \mathrm{p} / \mathrm{min}$; level $3=3,419 \mathrm{p} / \mathrm{min}$; and level 4=3,375 p/min (Still and Algahdi, 2003).

Klüpfel (2007) used another crowd modelling software (PedGo) for modelling and simulating crowd evacuation from the new Aljamarat Bridge, providing the duration of the evacuation (walking time) and distance covered 
by the evacuees during the process (Klüpfel, 2007). One of the worst-case scenarios was to evacuate 100,000 pilgrims (400 groups) evenly distributed on the bridge. The simulation showed the evacuation using the nearest exits took 10 minutes (Klüpfel, 2007), and assumed that all pilgrims were aware of all the nearest exits on the bridge and took the shortest path to these exits (Klüpfel, 2007).

Recently, Alazbah and Zafar (2019) proposed an ABM framework (using AnyLogic) to model and simulate congestion around Aljamarat Bridge pillars. They generated heterogeneous crowds of pilgrims (consisting of males and females, children, elderly, strong and weak), organised in groups that moved at different speeds. When groups do not finish their ritual according to the scheduled time, congestions at the bridge could occur. Hence, the authors simulated pilgrims and their behaviours at three crowd densities, normal, semi-crowded and crowded. The simulation considered agents interacting with the surrounding environment on the Aljamarat Bridge, including obstacles and other pilgrims. To assess the congestion on the bridge, the authors used the level of service (LoS), rated from A (free walking) to F (stampede). Their proposed solution was to signal the congestion levels using the traffic light model, green indicating comfortable walking, orange indicating moderate speeds and red indicating congestion. The paper did not report the number of pilgrims simulated in the model, nor any detailed results from the simulation (time spent inside the bridge, duration of the ritual and walking, whether the model considered normal or evacuation conditions).

The focus of this paper is to model and simulate the pilgrims at Aljamarat Bridge and test emergency evacuation scenarios using "ExtendSim", a DES tool.

\section{METHODOLOGY AND DATA SOURCES}

ExtendSim is a general-purpose simulation tool that provides a range of methodologies, such as, continuous; discrete event; discrete rate; and ABM simulations (Krahl, 2009; Krahl, 2012; Diba, 2018). ExtendSim's powerful platform for DES has been used to model a wide variety of systems, including manufacturing, healthcare, communications, logistics, or military services (Krahl and Nastasi, 2014). The basic idea for the model is that an item, progressing through the model, can be thought of as a workgroup which moves from block to block and performs a certain type of work (Briggisson, 2009). The type of workgroup depends on the attributes assigned to the item (Briggisson, 2009). ExtendSim was used here to analyse the sequenced activities of the stoning ritual at the Aljamarat Bridge. The ritual consists of entering the bridge (at a certain level depending on the pilgrim schedule), stoning the three pillars (which requires walking from one pillar to the other and queueing for stoning performance) then exiting the bridge. ExtendSim was used for our previous study (Owaidah et al., 2021) in modelling the Tawaf and Sayee rituals at the Grand Mosque at the beginning of the Hajj event.

Secondary data were obtained from The Institute of Hajj and Umrah Research and Ministry of Hajj, Makkah, Saudi Arabia. Various sources, statistics, reports, images, and video recording from Hajj 2015, 2016, 2017, and 2019 were used to validate the model.

\section{MODELLING AND SIMULATION IMPLEMENTATION 4.1. Aljamarat Bridge features}

The current Aljamarat Bridge was built between 2006 and 2010 (Al-kodmany, 2013). It is 950m long and 80m wide. Levels 1 to 4 are each about $12 \mathrm{~m}$ high and there are about 10m from level to level (Edrees, 2016; Alaska et al., 2017). There are 11 entry points, 12 exits, and six service towers along the bridge, including two helipad towers for medical emergency and emergency evacuation (Muller, 2015; Edrees, 2016). The bridge is designed to accommodate a maximum throughput of 125,000 pilgrims per hour per level (Ilyas, 2013). Each level of the bridge contains three pillars, each represented by a $26 \mathrm{~m}$ long wall: Al-Sughrah (small pillar); Al-Wustah (middle pillar); and Al-Kubrah or Al-Aqabah (large pillar) (Al-kodmany, 2011; Haase et al., 2019). The distance between the small and middle pillar is about $135 \mathrm{~m}$, and between the middle and large pillar is about 200m (Al-kodmany, 2011; Al-kodmany, 2013) as shown in Figure 1. Each side of the pillars allows for a maximum 788 pilgrims to perform the ritual at any time (Al-Haboubi, 2003).

At each pillar, pilgrims approach the target, positioning themselves at the edge of the basin surrounding the pillars (about $12 \mathrm{~m}$ from it). They then pelt the pillars (walls) with seven pebbles. On the 10th day only the first pillar is pelted, but on the next two days $\left(11^{\text {th }}\right.$ and $\left.12^{\text {th }}\right)$ each pillar is pelted with seven pebbles (Al-kodmany, 2011). Peak crowds for the ritual are around noon on each day (Al-kodmany, 2011).

Pilgrim groups are allocated specific routes for access, entry points, and levels for the ritual (Al-Bosta, 2011 and Al-Kodmany, 2011). The ground and $1^{\text {st }}$ floor of the bridge are used by pilgrims entering from the eastern side (from Mina tents or camps, $60 \%$ of the pilgrims); the $2^{\text {nd }}$ floor is used by the pilgrims coming from the western side (from Makkah, 10\%); the $3^{\text {rd }}$ floor is used by the pilgrims coming from the North of the bridge (from 
Almouasim tunnel, 20\%); and the $4^{\text {th }}$ floor is used by the pilgrims coming from the southern side (Al-Aziziah district, $10 \%)$.

\subsection{Aljamarat Bridge Three Pillar model: attributes, conditions and main ExtendSim blocks}

Evacuating mass crowds requires a safe, rapid, and smooth movement of a large number of participants from an area (a big arena, building, train station, city) when a dangerous situation arises (Friberg and Hjelm, 2014). This is independent of the nature of the danger (natural disasters, infrastructure accidents/failures, fires, attacks, etc.). For the Aljamarat Bridge, the following attributes, conditions, and blocks were used for the evacuation simulation: pilgrim establishment, age, walking speed, incident rates, distances, duration of ritual (stoning/pelting a pillar), and congestion conditions. They are detailed in Table 1. (Full model is available at: https://cloudstor.aarnet.edu.au/plus/s/n4abSUEMtE1qJXH)

Table 1. Main types of blocks included in the simulation model

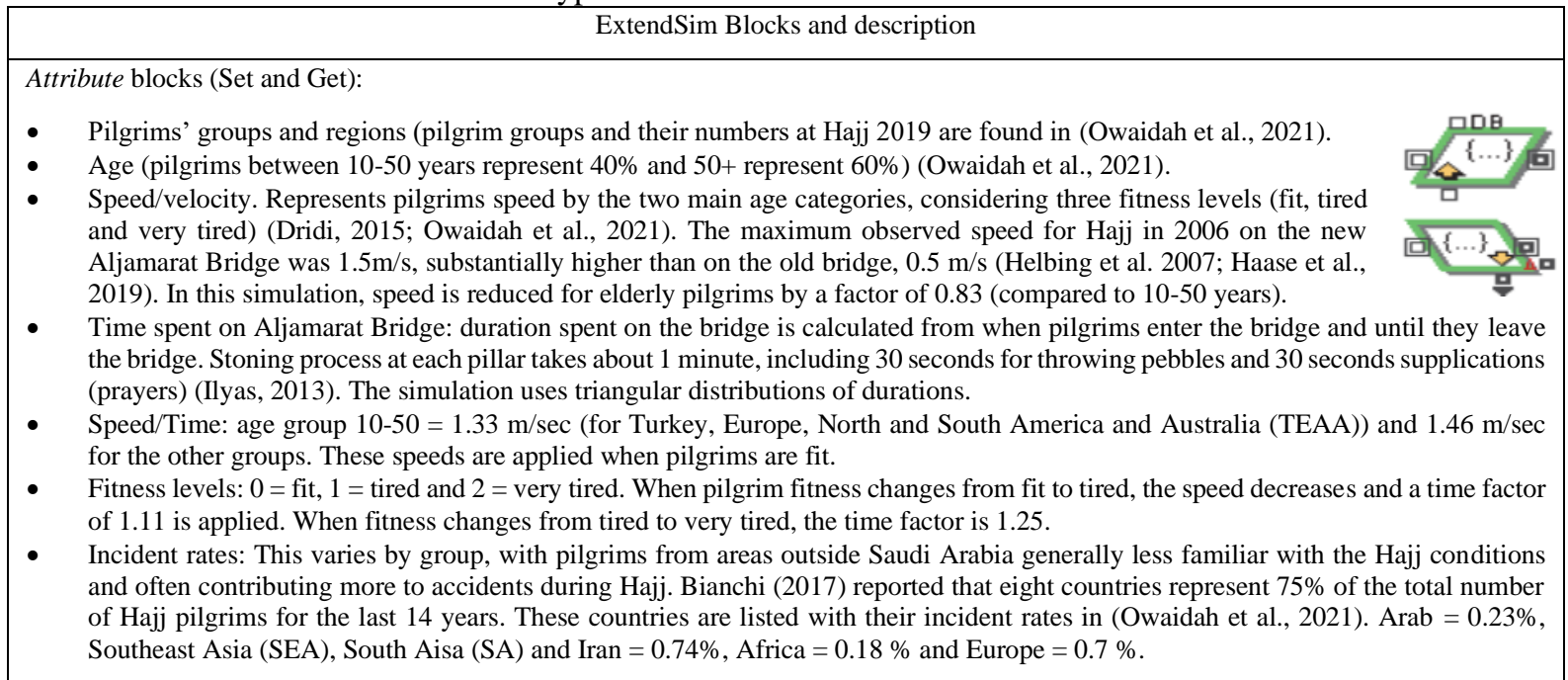

Select Out and Select In blocks for groups allocations or combinations

Each pilgrim group is allocated and scheduled

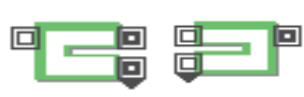

an entry to Aljamarat Bridge depending on their accommodation and paths to the bridge. GL and L1 receives Arabic Golf, Arab, SEA, SA, Iran, Africa and Locals, L2 Arab and Locals, L3 Arab, SEA, SA, Iran, TEAA and Locals and L4 SEA, SA, Iran and Locals.

Select Out blocks were included for the allocation of the pilgrims to the levels they may use, as

- $\quad$ L3

- $\quad$ GL and L1

- $\quad \mathrm{GL}, \mathrm{L} 1, \mathrm{~L} 2$ and L3

- $\quad$ GL, L1, L3 and L4

Select In blocks were used to combine streams of pilgrims using the same level.

Equation blocks

Walking to a pillar: These blocks are included to calculate the walking time to reach each of the pillars (e.g., the large pillar 3 is $700 \mathrm{~m}$ from the entrance) at each level of the bridge.

A random component was added in each situation to account for other influences in the duration of movement and rituals (e.g., heterogeneity within each group, possible crowding - LOS over 4 pilgrims $/ \mathrm{m}^{2}$ ). To calculate the walking time, the equation blocks consider simplified movement conditions. An example is provided here:

if(Incident $==0)$

walktime $=(\mathrm{d} /$ Average speed $) /$ ReduceSpeed $*$ Tired factor;

else

walktime $=2 *(\mathrm{~d} /$ Average speed $) /$ ReduceSpeed $*$ Tired factor;
Activity and Queue Blocks

Activity Blocks are used to represent activities such as walking or stoning the

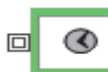

pillars. In this model, all activity blocks are set to a maximum 60 groups to perform the activity (based on the space available on each level of the bridge). Stoning (activity) blocks: represents the process of stoning/pelting a pillar on each level (stochastic process with an average of $1 \mathrm{~min}$ ).

Queue blocks: represents the process of queuing at a pillar on each level.

Plotter blocks: Plotter block: provide

information of the simulation

performance and outputs.

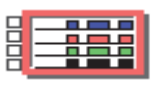

History blocks: provide information of the simulation performance and outputs.

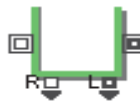

Exit blocks: there are five of these blocks at each level representing the exits of the bridge, as well as six blocks for the evacuation towers.

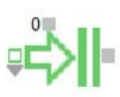




\section{MODEL VALIDATION AND DEVELOPING EVACUATION SCENARIOS}

Cuesta et al. (2016) indicated three methods used to develop new scenarios for evacuation models: applying legacy models; improving current models; or developing new evacuation models. In addition, the evacuation scenarios consider how human movement is incorporated, either as flow-based, cellular automata (CA), ABM, or activity-based models; also, the level of aggregation could be macro-, micro-, and effect-based. Our choice was to modify a 'base' model and develop a new evacuation model, using the six evacuation towers in the process, which is different from the normal exits from the bridge by levels. Our research approaches the activity-based and macro-level description for a new model, to offer managerial solutions in case of evacuation at the Aljamarat Bridge. Figure 2 provides the location of the towers, all of them with the same capacity. The evacuation model was built on a validated model, incorporating additional Activity blocks to mimic

\section{DISCUSSION}

A validated model showed that the completion of the ritual of stoning the three pillars in a safe manner, mimicking the three million pilgrims, can be achieved in 22 hours (average of more than 100 runs). This is because all pilgrim groups followed strict scheduling and each group was able to finish their ritual within 12-14 minutes, assuming no crowding. As a result, the ritual was completed in less time than at the Hajj 2019 and less than the simulation setup run (Table 2).

Table 2. Aljamarat Bridge Validation

\begin{tabular}{|c|c|c|c|c|c|c|}
\hline \multirow[t]{2}{*}{ Levels } & \begin{tabular}{|c|} 
Real Data \\
2019
\end{tabular} & Sim. results & $\begin{array}{c}\text { Diff. } \\
\%\end{array}$ & \begin{tabular}{|c|} 
Real Data \\
2019
\end{tabular} & $\underset{(\text { min })}{\text { Sim. Results }}$ & $\begin{array}{c}\text { Diff. (from } \\
60 \text { min) } \\
(\text { min })\end{array}$ \\
\hline & \multicolumn{3}{|c|}{$\begin{array}{c}\text { Percentages of pilgrims/24h (\%) } \\
\text { and number of groups (in } \\
\text { brackets) }\end{array}$} & \multicolumn{3}{|c|}{$\begin{array}{l}\text { Av. and std.dev. duration of ritual } \\
\text { activity for each group (entering the } \\
\text { bridge, walking between the pillars, } \\
\text { stoning all pillars and exiting) (*) }\end{array}$} \\
\hline L4 & $10(1,200)$ & $9.38(1,125)$ & -0.26 & \multirow{5}{*}{$\begin{array}{c}1-3 \text { hours } \\
(*)\end{array}$} & $12.89(1.88)$ & -47.11 \\
\hline $\mathbf{L 3}$ & $20(2,400)$ & $20.44(2,452)$ & 0.44 & & $13.08(2.03)$ & -46.92 \\
\hline L2 & $10(1,200)$ & $9.61(1,153)$ & -0.39 & & $12.93(1.85$ & -47.07 \\
\hline L1 & $30(3,600)$ & $30.36(3,643)$ & 0.36 & & $13.76(2.57)$ & -46.24 \\
\hline GL & $30(3,600)$ & $30.21(3,627)$ & 0.21 & & $13.89(2.64)$ & -46.11 \\
\hline
\end{tabular}

Two additional models were tested with scheduled arrivals, but even use of the five levels; and with stochastic (Poisson arrivals across the day). The results confirm the expectation that even use of the levels leads to a better utilisation and a statistically significant reduction of 0.4 min, whereas the stochastic arrivals do not have a significant impact (substantial reserves of capacity on the bridge).

For the evacuation models, the following conditions were assumed:

- pilgrims about to enter the bridge are evacuated through the ramps (not proceeding through the five levels);

- pilgrims who finished the ritual exit the bridge according to the set pathways/ramps, but at a higher speed (a multiplier of 1.1); pilgrim movements to the nearest towers during the evacuation process. These blocks are linked to Equation blocks specifying the walking times to the towers.

As our model structure is similar to our previous work for Tawaf and Sayee rituals (Owaidah et al., 2021), we apply a limit on the evacuation speed as $1.5 \mathrm{~m} / \mathrm{s}$. We assume that the groups proceed to the nearest tower from the location of evacuation and that they are informed through planning, training and messaging which the nearest tower is. A prior allocation is set, with simple rules such as no intersection of the evacuation pathways or balanced/ "as even as possible" utilisation of all exits. Pilgrims can access the towers from all levels, whereas the ramps have direct access only to certain levels. The evacuation scenarios tested in this model evacuates pilgrims from all levels using the evacuation towers.

- pilgrims performing the ritual at any of the five levels during evacuation will use one of the six towers on both sides of the bridge, as per allocation and instructions.

The results presented here refer to evacuating the pilgrims inside the bridge, which is the most challenging task, given the confined space. The evacuation scenario considered various numbers of pilgrims on the bridge (scheduled or stochastic arrivals), and various number of towers being used for evacuation. The model explored the evacuation times, assuming several discrete starting times for the evacuation, every two hours (60 min, $180 \mathrm{~min}$, etc. until the end of time window for the ritual). The results in Tables 3 and 4 include the average evacuation duration from each tower from two scheduling scenarios, (scheduled arrivals and Poisson) considering a LOS on the bridge of $4 \mathrm{p} / \mathrm{m}^{2}$. They also present the number of groups evacuated by tower, suggesting a balanced used of the facilities, through the rules included in the model (closest tower, no intersection of flows, no further incidents). Consequently, the average evacuation durations from all towers varied between 9.97 to 10.48 mins. The results show that the evacuation was carried out smoothly without any crowds building, as the total number of pilgrims on the bridge has not exceeded 327 thousand on the five levels. The larger durations for normal proceedings reflect the inclusion of the stoning ritual, which is not performed during evacuation. The pilgrim groups were exiting from the towers using paths designated for them (Figure 2).

Other evacuation scenarios were developed by generating the pilgrims' groups randomly, but at more intense rates, or with fewer (4-5) towers (not shown here, but available upon request and presented at the conference). The average evacuation durations from all towers were between 11.20 to 15.35 mins, depending on the number of towers available for evacuation. The results confirm the importance of scheduling method to control for crowd 
levels on the bridge and that by closing 1-2 towers, the evacuation takes much longer.

Figure 3 presents the duration of completing the ritual in normal conditions using scheduled arrivals according to the allocated distribution on the bridge (Table 2) and with even distribution across the five levels. Unsurprisingly, even use of the levels shows better flow of pilgrims on the bridge and no build-up congestion around the pillars, with an average reduction of $0.4 \mathrm{~min}$ the duration of the ritual. On the other hand, the duration of evacuation the pilgrims using scheduled arrivals and Poisson with an average rate of 600 groups/hour are similar, and slowly building up towards the end of the time window for the ritual.

\begin{tabular}{|c|c|c|c|c|c|c|c|}
\hline \multirow{2}{*}{$\begin{array}{l}\text { Evacuation } \\
\text { starting } \\
\text { time }\end{array}$} & \multirow{2}{*}{$\begin{array}{c}\text { Evacuation } \\
\text { duration } \\
(\mathrm{min})\end{array}$} & \multicolumn{6}{|c|}{ Average number of groups by tower } \\
\hline & & $\begin{array}{c}\text { Tower } \\
1\end{array}$ & $\begin{array}{c}\text { Tower } \\
2\end{array}$ & $\begin{array}{c}\text { Tower } \\
3\end{array}$ & $\begin{array}{c}\text { Tower } \\
4\end{array}$ & $\begin{array}{c}\text { Tower } \\
5\end{array}$ & $\begin{array}{c}\text { Tower } \\
6\end{array}$ \\
\hline 60 & 10.18 & 211 & 218 & 188 & 189 & 182 & 213 \\
\hline 180 & 10.26 & 211 & 218 & 188 & 189 & 182 & 213 \\
\hline 300 & 10.35 & 211 & 218 & 188 & 189 & 182 & 213 \\
\hline 420 & 10.3 & 211 & 217 & 187 & 188 & 182 & 213 \\
\hline 540 & 10.29 & 211 & 217 & 187 & 188 & 182 & 213 \\
\hline 660 & 10.48 & 211 & 217 & 187 & 188 & 182 & 213 \\
\hline 780 & 10.41 & 211 & 217 & 187 & 188 & 182 & 213 \\
\hline 900 & 10.33 & 211 & 217 & 187 & 188 & 182 & 213 \\
\hline 1,020 & 10.24 & 211 & 217 & 187 & 188 & 182 & 213 \\
\hline 1,140 & 9.97 & 116 & 108 & 92 & 100 & 90 & 94 \\
\hline
\end{tabular}

\begin{tabular}{|} 
Table 4. Duration of evacuation and number groups using six \\
towers (random arrivals - Poisson 600 groups/hour) \\
\begin{tabular}{|c|c|c|c|c|c|c|}
\hline $\begin{array}{c}\text { Evacuation } \\
\text { duration } \\
\text { (min) }\end{array}$ & \begin{tabular}{c} 
Average number of groups by tower \\
\cline { 2 - 7 }
\end{tabular} & $\begin{array}{c}\text { Tower } \\
1\end{array}$ & $\begin{array}{c}\text { Tower } \\
2\end{array}$ & $\begin{array}{c}\text { Tower } \\
\text { Tower }\end{array}$ & $\begin{array}{c}\text { Tower } \\
\text { Tower }\end{array}$ & $\begin{array}{c}\text { Tower } \\
5\end{array}$ \\
\hline 10.20 & 223 & 243 & 210 & 207 & 199 & 226 \\
\hline 10.28 & 220 & 234 & 204 & 200 & 191 & 224 \\
\hline 10.37 & 215 & 231 & 198 & 198 & 188 & 220 \\
\hline 10.29 & 209 & 215 & 187 & 188 & 177 & 210 \\
\hline 10.29 & 214 & 221 & 193 & 193 & 186 & 218 \\
\hline 10.3 & 214 & 221 & 194 & 193 & 186 & 218 \\
\hline 10.29 & 207 & 215 & 185 & 187 & 176 & 208 \\
\hline 10.35 & 211 & 218 & 188 & 190 & 181 & 214 \\
\hline 10.29 & 214 & 223 & 194 & 193 & 186 & 218 \\
\hline 10.32 & 214 & 225 & 196 & 193 & 186 & 218 \\
\hline
\end{tabular}
\end{tabular}

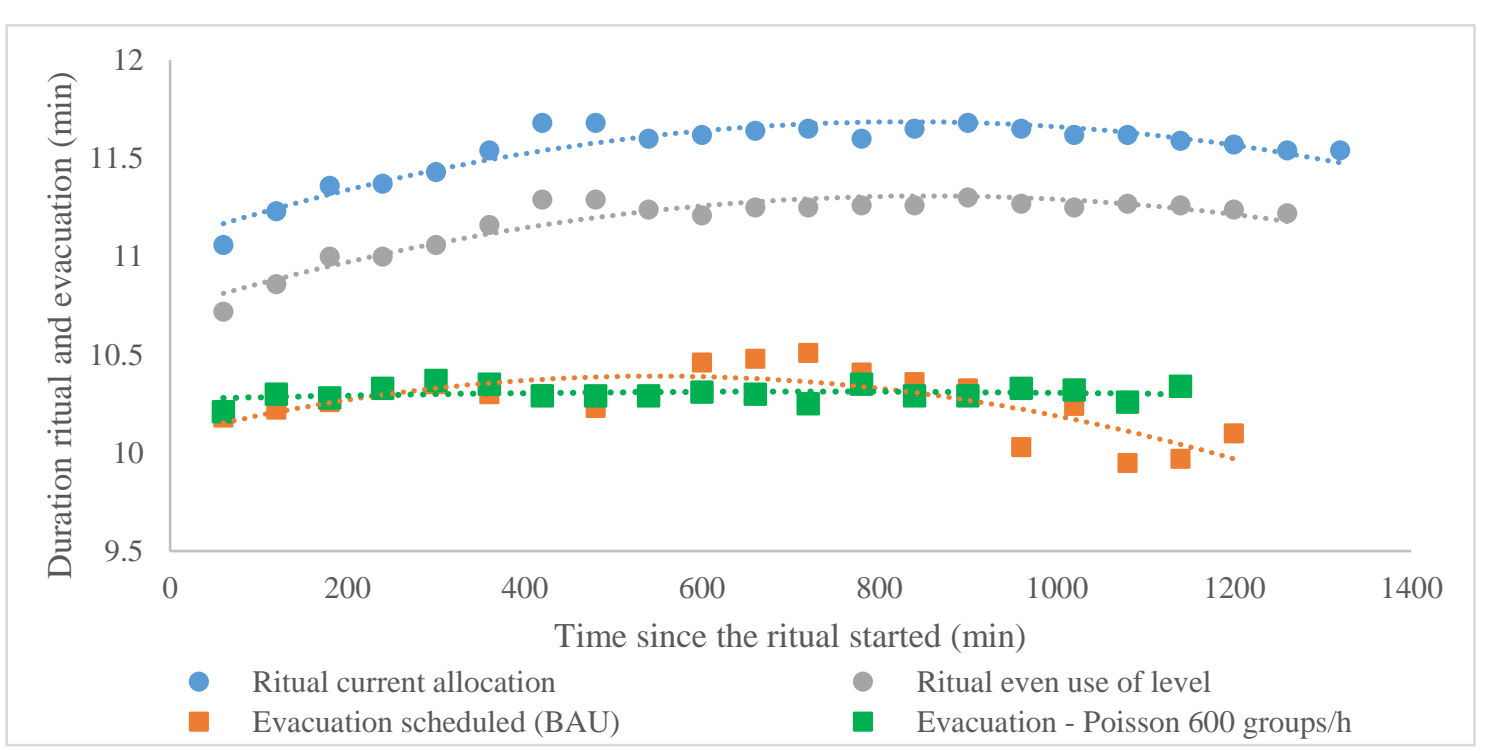

Figure 3. Evacuated pilgrims and evacuation (BAU) durations

\section{CONCLUSION}

The stoning ritual is performed at the Aljamarat Bridge during the last three days of Hajj. This bridge has witnessed serious crowd incidents in the past, which led to the reconstruction of the bridge in its current form to improve safety. Yet incidents can happen that can require pilgrims to be evacuated. This paper focused on the development of evacuation modelling and simulation in case of any hazardous situations on the bridge, using DES tool (ExtendSim). The rituals can be performed under $14 \mathrm{~min}$ in normal conditions, and even distribution to the five levels improves the proceedings. In our models, we proposed that pilgrims can be evacuated using six towers linked to the bridge on both sides. During the evacuation, the pilgrims approach the nearest tower to exit by following easy directed routes that do not conflict or intersect with others. From the evacuation scenarios, it was noticed that the evacuated number of pilgrims in the scenario with random arrivals was higher than the number of pilgrims in the scheduled situation (status quo/BAU), although the evacuation time was comparable. The evacuation time increases when arrivals are intensified in the first part of the day of the ritual and when certain conditions may lead to closure of the helipad towers.

The scenarios showed in Figure 3 indicate evacuation times shorter than those reported in the Klüpfel study, which evacuated 100,000 pilgrims in 10 mins. The model did not present any crowd queueing and waiting during the evacuation because the bridge has enough capacity to accommodate the current number of pilgrims. However, closing helipad towers will increase the duration of the evacuation. Future research could focus on developing 
evacuation modelling from the Aljamarat Bridge on the first day of the stoning ritual, which requires stoning only the large pillar and a shorter time window (12 hours).

\section{ACKNOWLEDGEMENTS}

The authors are grateful to the Ministry of Hajj for providing data for this research. The authors would also like to thank Kathi Hansen, the academic representative of Imagine That Inc., for granting access to ExtendSim software for this research.

\section{REFERENCES}

Alabdulkarim, L., Alrajhi, W., \& Aloboud, E. (2016). Urban Analytics in Crowd Management in the Context of Hajj. In Int. Conf. Social Computing and social media, 249-257, Springer, Cham. AlGadhi, S. \& Still, K., 2003. Jamarat Bridge; Mathematical Models, Computer Simulation and Hajjis Safety Analysis. Technical Report, Crowd Dynamics Limited.

Al-Haboubi, M. H., 2003. A new layout design for the Jamarat area (stoning the Devil). Arabian Journal for Science and Engineering, 28(2), 131-142.

Al-Kodmany, K., 2011. Planning for safety: The case of the symbolic stoning of the devil in Hajj. Journal of Architectural and Planning Research, 28(1), 28-43.

Al-Kodmany, K., 2013. Crowd management and urban design: New scientific approaches. Urban Design International, 18(4), 282-295.

Alshammari, S. M. \& Mikler, A. R., 2015. Modeling disease spread at global mass gatherings: Hajj as a case study. 2015 International Conference on Healthcare Informatics (ICHI). Dallas, TX, 574-577.

Aitsi-Selmi, A., Murray, V., Heymann, D., McCloskey, B., Azhar, E. I., Petersen, E., ... \& Dar, O. (2016). Reducing risks to health and wellbeing at mass gatherings: the role of the Sendai Framework for Disaster Risk Reduction. International Journal of Infectious Diseases, 47, 101-104.

Cuesta, A., Abreu, O., \& Alvear, D., 2016. Future challenges in evacuation modelling, in Evacuation Modeling Trends. Cham, Switzerland: Springer, 103-129.

Bianchi, R., 2017. Reimagining the Hajj. Social Sciences, 6(2), 2-26.

Diba, K., 2018. A comparative study of business process simulation tools. Master's thesis, University of Hasselt.

Dridi, M. H., 2014. Pedestrian flow simulation validation and verification techniques. arXiv preprint arXiv:1410.0603.

Edrees, M., 2016. The role of urban design in crowd control: Case study 'Jamarat area'. Available at https://www.researchgate.net/publication/310346287_The_Role_of_Urban_Design_in_Crowd_Control_Case_Study_J amarat_Area

Felemban, E. A., Rehman, F. U., Biabani, S. A. A., Ahmad, A., Naseer, A., Majid, A. R. M., Hussain, O. K., Qamar, A. M., Falemban, R. and Zanjir, F., 2020. Digital revolution for Hajj crowd management: a technology survey. IEEE Access, 8, 208583-208609.

Friberg, M., \& Hjelm, M., 2014. Mass evacuation-human behavior and crowd dynamics. Department of Fire Safety Engineering, Lund University, Sweden, 12.

Haase, K., Kasper, M., Koch, M., \& Müller, S. (2019). A Pilgrim Scheduling Approach to Increase Safety During the Hajj. Operations Research, 67(2), 376-406.

Ilyas, Q. M., 2013. A Netlogo model for ramy al-jamarat in Hajj. Journal of Basic and Applied Scientific Research, 3(12), 199-209.

Klüpfel, H., 2007. The simulation of crowd dynamics at very large events - Calibration, empirical data, and validation. In Pedestrian and evacuation dynamics 2005 (pp. 285-296). Springer, Berlin, Heidelberg.

Krahl, D., 2009. ExtendSim advanced techology: discrete rate simulation. In Proceedings of the 2009 Winter Simulation Conference (WSC) (pp. 333-338). IEEE.

Krahl, D., 2012. ExtendSim: a history of innovation. In Proceedings of the Winter Simulation Conference (WSC '12). Winter Simulation Conference, 1-8, IEEE

Krahl, D., \& Nastasi, A., 2014. Reliability Modeling with ExtendSim. In Proceedings of the 2014 Winter Simulation Conference, 4219-4225, IEEE.

Khozium, M., Abuarafah, A. \& AbdRabou, E., 2012. A proposed computer-based system architecture for crowd management of pilgrims using thermography. Life Science Journal, 9(2), 377-383.

Memish, Z. A., Stephens, G. M., Ste_en, R. \& Ahmed, Q. A., 2012. Emergence of medicine for mass gatherings: Lessons from the Hajj. The Lancet Infectious Diseases, 12(1), 56-65

Müller, S., 2015. Spaces of rites and locations of risk: the great pilgrimage to Mecca. In The Changing World Religion Map, 841-853. Springer, Dordrecht.

Osman, M., \& Shaout, A., 2014. Hajj Guide Systems-Past, Present and Future. International Journal of Emerging Technology and Advanced Engineering, 4(8), 25-31.

Owaidah, A., Olaru, D., Bennamoun, M., Sohel, F., \& Khan, N., 2019. Review of modelling and simulating crowds at mass gathering events: Hajj as a case study. Journal of Artificial Societies and Social Simulation, 22(2).

Owaidah, A., Olaru, D., Bennamoun, M., Sohel, F., \& Khan, R. N. (2021). Modelling mass crowd using discrete event simulation: A case study of integrated tawaf and sayee rituals during Hajj. IEEE Access.

Reffat, R., 2012. An Intelligent Computational Real-time Virtual Environment Model for Efficient Crowd Management. International Journal of Transportation Science and Technology, 1(4), 365-378.

Yamin, M., \& Albugami, M. A., 2014. An architecture for improving Hajj management. In International Conference on Informatics and Semiotics in Organisations, 187-196. Springer, Berlin, Heidelberg. 